\title{
A Bi-national Analysis of 252 Pancreatic Resections for Chronic Pancreatitis with Regard to Incidental Carcinoma Sequence and Overall Postoperative Outcome
}

\author{
THOMAS MALINKA ${ }^{1}$, FRITZ KLEIN ${ }^{1}$, TRANG LE THU ${ }^{1}$, CHRISTINA S. RÖSCH ${ }^{2}$, HELWIG WUNDSAM ${ }^{2}$, \\ MATTHIAS BIEBL ${ }^{1}$, JOHANN PRATSCHKE ${ }^{1}$, MARCUS BAHRA ${ }^{1}$ and REINHOLD FÜGGER ${ }^{2}$ \\ ${ }^{1}$ Department of Surgery, Campus Mitte/Campus Virchow, Charité University Hospital, Berlin, Germany; \\ ${ }^{2}$ Department of Surgery, Elisabethinen Hospital Linz, Linz, Austria
}

\begin{abstract}
Background/Aim: Numerous treatment algorithms for patients with chronic pancreatitis are still debated. In particular, surgical therapy is often only considered after long-term conservative treatment. The aim of this study was the bi-national analysis of patients who underwent pancreatic resection for suspected chronic pancreatitis at an Austrian and a German high-volume center with regard to overall postoperative outcome and incidental carcinoma sequence. Patients and Methods: Overall, 252 consecutive pancreatic resections for suspected chronic pancreatitis were performed at the two institutions between 2005 and 2015. In a bi-national retrospective analysis, postoperative results as well as histopathological findings were analyzed. Results: Pancreatic resections were performed in 193 male (76.6\%) and 59 female patients (23.4\%), with a median age of 53.2 years. A total of 175 resections of the pancreatic head (69.4\%), 37 distal pancreatectomies (14.7\%), 23 total pancreatectomies $(9.1 \%)$ and 18 other pancreatic resections (7.1\%) were performed within our study period. Postoperative complications Clavien-Dindo grade II or greater occurred in 94 patients (37.3\%). Twenty-one patients (8.3\%) developed clinically relevant postoperative pancreatic fistula (grade $B$ and $C$ ), while postoperative mortality occurred in four patients (1.6\%). Final histological examination of the operative specimen revealed incidental pancreatic adenocarcinoma in 18 out of the 252 patients (7.1\%). Conclusion: The results of our study demonstrate
\end{abstract}

Correspondence to: Thomas Malinka, Department of Surgery, Charité Campus Mitte and Charité Campus Virchow Klinikum, Charité Universitätsmedizin Berlin, Campus Virchow-Klinikum, Augustenburger Platz 1, 13353 Berlin, Germany. Tel: +49 30450552001, e-mail: Thomas.Malinka@charite.de

Key Words: Chronic pancreatitis, resection, incidental carcinoma, outcome. that pancreatic resections for chronic pancreatitis may nowadays be considered technically feasible and safe. The high incidence of incidental pancreatic adenocarcinoma especially underlines the necessity for an early surgical therapeutic approach for these patients.

Chronic pancreatitis (CP) is a progressively evolving inflammation of the pancreas along with destruction of the pancreatic parenchyma and its replacement by fibrotic tissue that results in progressive loss of endocrine and exocrine functionality (1). Pathophysiological mechanisms of CP are complex and potential causes may include toxic factors such as alcohol or smoking, genetics, metabolic or idiopathic abnormalities, and autoimmune responses (2-4). Functional consequences include recurrent or constant abdominal pain, diabetes mellitus and maldigestion (5). Possible complications include dilatation, distortion and stricture of the pancreatic ducts, calcification of the pancreatic parenchyma, formation of pseudocysts, duodenal or common bile duct stenosis, or the formation of superior mesenteric, portal or splenic vein thrombosis which may each severely affect the patient's quality of life and overall prognosis $(1,6)$. In addition, $\mathrm{CP}$ is considered a risk factor for pancreatic cancer, whereas the overall incidence of cancer occurrence remains unspecified (7, 8). Recommendations for screening of patients with CP for pancreatic cancer do not exist and, due to a wide diversity of clinical and morphological presentations of $\mathrm{CP}$, the differentiation between $\mathrm{CP}$ and pancreatic cancer, especially in cases when malignant tumor growth appears in the course of CP, is challenging (4). Due to the lack of high-quality randomized controlled trails, there are still no evidence-based guidelines. The decision of subsequent intervention is therefore mainly based on individual preference and expertise of the treating physician or institution. Currently, numerous options, including medical, radiological, endoscopic and surgical interventions, mainly targeting symptom control and pain relief, are practiced (9). 
The objective of this study was a bi-national evaluation of patients who underwent pancreatic resections for suspected $\mathrm{CP}$ at an Austrian and a German high-volume center with special regard to incidental carcinoma sequence and overall postoperative outcome.

\section{Patients and Methods}

Patient inclusion criteria, definition and data collection. This was a retrospective bi-national (Germany and Austria) analysis conducted at two tertiary referral centers for pancreatic surgery. All patients undergoing pancreatic resection between January 2005 and December 2015 for suspected CP were entered into a prospective database and retrospectively analyzed. Written informed consent was obtained from all patients. The diagnosis of $\mathrm{CP}$ was based on clinical, morphological and functional parameters according to the English language version of the S3-consensus guidelines on $\mathrm{CP}$ (10). Standard preoperative clinical diagnostics included physical examination and routine laboratory testing, including levels of amylase and the tumor marker CA19-9. Ultrasonography, endosonography, computed tomography and magnet resonance imaging were routinely used as radiological diagnostic tools. Indications for pancreatic resection were endorsed in an interdisciplinary consensus meeting. All included operations were performed by experienced pancreatic surgeons at the corresponding study site and all procedures were performed in open surgical technique according to international standards at that time. There were no minimal-invasive pancreatectomies in the study group. Accordingly, within the study period, we identified and reviewed a total of 252 patients as part of a retrospective study design.

Surgical technique. At the beginning of the operation, peritoneal metastases were initially excluded by complete exploration of the abdominal cavity. Access to the omental bursa was established by dissection of the gastrocolic ligament. After retraction of the stomach and inspection of the pancreas, local resectability of the lesion and the extent of the resection were determined based on local findings. Dissection of the pancreas was performed either by electrocautery or scalpel, or in some cases of pancreatic left resection with a stapling device. A standard lymphadenectomy was performed. In the case of a pancreatoenteral anastomosis, either a pancreatojejunostomy or a pancreatogastrostomy was performed depending on the individual surgeon's preference. Distal closure of the pancreatic remnant included various techniques within the study period, consisting of: direct closure of pancreatic duct by suture; suture of pancreatic duct and fish-mouth closure of pancreatic remnant; as well as stapling devices. Linear stapling devices armed with a $60-\mathrm{mm}$ cartridge (EndoGIA ${ }^{\mathrm{TM}}$; Auto-Suture, Covidien, Minneapolis, MN, USA) reinforced by a bioabsorbable mesh (SEAMGUARD ${ }^{\circledR}$; W.L. Gore, Flagstaff, AZ, USA) were used. Longitudinal pancreatojejunostomy was performed using the Partington-Rochelle technique as previously described (11). Every patient received at least one intra-abdominal drain (Degania Silicone Europe $\mathrm{GmbH}$, Regensburg, Germany) to measure postoperative amylase level and drain output in the postoperative course.

Standard postoperative care. Postoperative care was standardized at both hospitals. All patients were monitored for at least 1 day at a specialized surgical intensive care unit. Amylase level was monitored in the serum and in the intraoperatively placed abdominal drains on the second postoperative day. In the absence of signs of a postoperative pancreatic fistula (POPF), oral food intake was started depending on the clinical presentation and tolerance. The concept of enhanced recovery after surgery (ERAS) was not applied during the study period (12).

Data collection. The following data were collected for each patient: demographics (age, gender); underlying diagnosis; preoperative endoscopic retrograde cholangio-pancreatography (ERCP) and stenting; routine laboratory testing, including bilirubin, amylase and the tumor marker CA19-9; surgical procedure; results of the final histopathological examination, including TNM classification in case of underlying malignancy; operative details such as operative time; details of the perioperative course such as postoperative morbidity in terms of POPF and postpancreatectomy hemorrhage (PPH), which were all classified according to International Study Group of Pancreatic Fistula definitions $(13,14)$; the length of hospital stay was calculated from the day of surgery until the day of discharge; long-term follow-up was assessed by our oncological outpatient clinic, with review of medical records as well as direct communication with the general practitioner tracking patient survival or the documented day of death.

Statistical analysis. Statistics are presented as mean (range) or numbers (\%). Student's $t$-test or Wilcoxon signed-rank test was used to compare means of quantitative variables as appropriate. Categorical data were compared using chi-square tests or Fisher's exact tests as appropriate. Survival analysis was performed using the Kaplan-Meier method (log-rank test). Significance tests were two-sided, and values of $p<0.05$ were considered to be statistically significant. All statistical analyses were performed using SPSS version 24.0 (IBM Corp., Armonk, NY, USA).

\section{Results}

Baseline characteristics. Between January 2005 and December 2015, a total of 252 consecutive patients underwent pancreatic resections for suspected $\mathrm{CP}$ at Austrian and German highvolume Centers; among them, 175 patients underwent pancreaticoduodenectomy, 37 distal pancreatectomy, 23 total pancreatectomy and 18 patients underwent other pancreatic operations, mainly consisting of longitudinal pancreatojejunostomy with the Partington-Rochelle technique. There were 193 males and 59 females, with a mean age of 52 (range=19-85) years for this group. A total of 148 patients $(58.7 \%)$ underwent ERCP prior to surgery, with 128 patients $(50.8 \%)$ requiring interventional pancreatic or biliary stenting in the preoperative course. Routine laboratory testing revealed a mean preoperative bilirubin level of 1.2 (range $=0.1-17.9) \mathrm{mg} / \mathrm{dI}$, while the mean preoperative amylase and CA19-9 levels were 104.9 (range $=0$ 916) $\mathrm{U} / \mathrm{l}$ and 79.8 (range=3-798) kU/l, respectively.

Perioperative and postoperative data. Type of resection, operating time, histology and specific complications in terms of postoperative pancreatic fistula (grade B and C), postpancreatectomic hemorrhage and postoperative bile 
leakage choledochojejunostomy are stated in Table I. Furthermore, complications according to the Clavien-Dindo classification (greater than grade $>2$ ) (15), length of hospital stay, reoperation within 30 days, and 30-day mortality are depicted.

Direct comparison of patients with $\mathrm{CP}$ alone and those with $\mathrm{CP}$ with incidental carcinoma revealed significant differences. With reference to age $(p=0.001)$, patients with $\mathrm{CP}$ with incidental carcinoma were significantly older, while their mean preoperative levels of bilirubin $(p=0.001)$ and CA $19-9$ ( $p=0.001)$ were significantly higher. Mean preoperative amylase levels did not differ $(p=0.659)$ between groups Preoperative ERCP $(p=0.576)$ and preoperative pancreatic or biliary stenting ( $p=0.562)$ was comparable in both groups. Furthermore, POPF $(p=0.577)$, PPH $(p=0.684)$ and postoperative bile leakage $(p=0.556)$ did not differ between groups. The number of patients with complications according to the Clavien-Dindo classification (Clavien-Dindo $>2$ ) was not significantly different ( $p=0.332$ ). Additionally, the mean hospital stay $(p=0.411)$, necessity for reoperation within 30 days $(p=0.481)$ and 30 -day mortality rates demonstrated no significant differences between the two groups $(p>0.99)$ (Table II).

Further assessment of patients in whom final histological examination showed ductal adenocarcinoma revealed complete resection of tumor tissue in 13 cases, while in five patients, residual tumor was present microscopically at retroperitoneal resection margins (Table III). Evaluation of mean overall survival demonstrated a clear disadvantage for patients with $\mathrm{CP}$ and incidental carcinoma (11.7 vs. 216.1 months; $p=0.001$ ) (Figure 1).

\section{Discussion}

In this study, we demonstrate that pancreatic resection for $\mathrm{CP}$ may be considered a safe and feasible procedure with low mortality rates. The high incidence of incidental pancreatic adenocarcinoma underlines the necessity for an early surgical therapy and recommends it as an efficient treatment approach.

$\mathrm{CP}$ is a fibro-inflammatory disease of the pancreas leading to exocrine and endocrine insufficiency with functional consequences, including recurrent or constant abdominal pain, diabetes mellitus or maldigestion in most patients (1). Furthermore, CP is considered a risk factor for pancreatic cancer and subsequent overall long-term prognosis is limited. Although significant progress in pathophysiological understanding of CP has been achieved in recent years, evidence-based guidelines for clinical treatment standards are lacking, especially due to a dearth of high-quality randomized controlled trails (4). Accordingly, clinical decision-making varies among pancreatic centers and numerous treatment options including medical, radiological, endoscopic and surgical interventions are implemented
Table I. Operative details, postoperative complications and clinical course.

\begin{tabular}{lc}
\hline Characteristic & $\mathrm{n}=252$ \\
\hline Type of resection, $\mathrm{n}(\%)$ & \\
Pancreaticoduodenectomy & $175(69.4)$ \\
Distal pancreatectomy & $37(14.7)$ \\
Total pancreatectomy & $23(9.1)$ \\
Other & $18(7.1)$ \\
Mean operating time $( \pm \mathrm{SD})$, min & \\
Pancreaticoduodenectomy & $356.9 \pm 73.1$ \\
Distal pancreatectomy & $202.2 \pm 40.6$ \\
Total pancreatectomy & $395.7 \pm 120.1$ \\
Other & $196.8 \pm 61.5$ \\
Histology, n (\%) & \\
Chronic pancreatitis & $234(92.9)$ \\
Ductal adenocarcinoma & $18(7.1)$ \\
Postoperative pancreatic fistula (grade B and C), $\mathrm{n}(\%)$ & $21(8.3)$ \\
Postpancreatectomic hemorrhage, $\mathrm{n}(\%)$ & $17(6.7)$ \\
Postoperative bile leakage choledochojejunostomy, $\mathrm{n}(\%)$ & $12(4.8)$ \\
Complication ${ }^{\#}, \mathrm{n}(\%)$ & $94(37.3)$ \\
Mean length of hospital stay (range), days & $17.6(7-276)$ \\
Reoperation within 30 days, $\mathrm{n}(\%)$ & $22(8.7)$ \\
30-Day mortality, $\mathrm{n}(\%)$ & $4(1.6)$ \\
\hline
\end{tabular}

\#Clavien-Dindo grade $\geq 2$.

depending on the individual preference of the primary treating physician (16).

The diagnosis of $\mathrm{CP}$ is usually confirmed by imaging technologies. From our observations, endosonography, computed tomography and magnetic resonance imaging were the preferred diagnostic modalities for assessing morphological abnormalities of the pancreas, which is in line with recommendations from recent guidelines (17). While ERCP has the highest diagnostic sensitivity of all imaging modalities for detection of $\mathrm{CP}, \mathrm{ERCP}$ is an invasive technique, with the risk of procedure-associated complications, such as post-ERCP pancreatitis (10). In our study, $58.7 \%$ of patients underwent preoperative ERCP and $50.8 \%$ of patients underwent preoperative pancreatic or biliary stenting mainly due to delayed surgical consultation. Cahen et al. demonstrated surgical drainage of the pancreatic duct as being more effective than endoscopic treatment in patients with obstruction of the pancreatic duct due to $\mathrm{CP}$, which is in accordance to our proceeding (18). Furthermore, in the long term, they reported that patients with $\mathrm{CP}$ who underwent surgery as initial treatment had more relief from pain, with fewer overall procedures, than patients who were treated endoscopically. In addition, almost half of the patients with endoscopic interventions eventually underwent surgery in the further treatment course. They also concluded that the general perception that endoscopic treatment is less invasive than surgery cannot be sustained (19). Rutter et al., who 


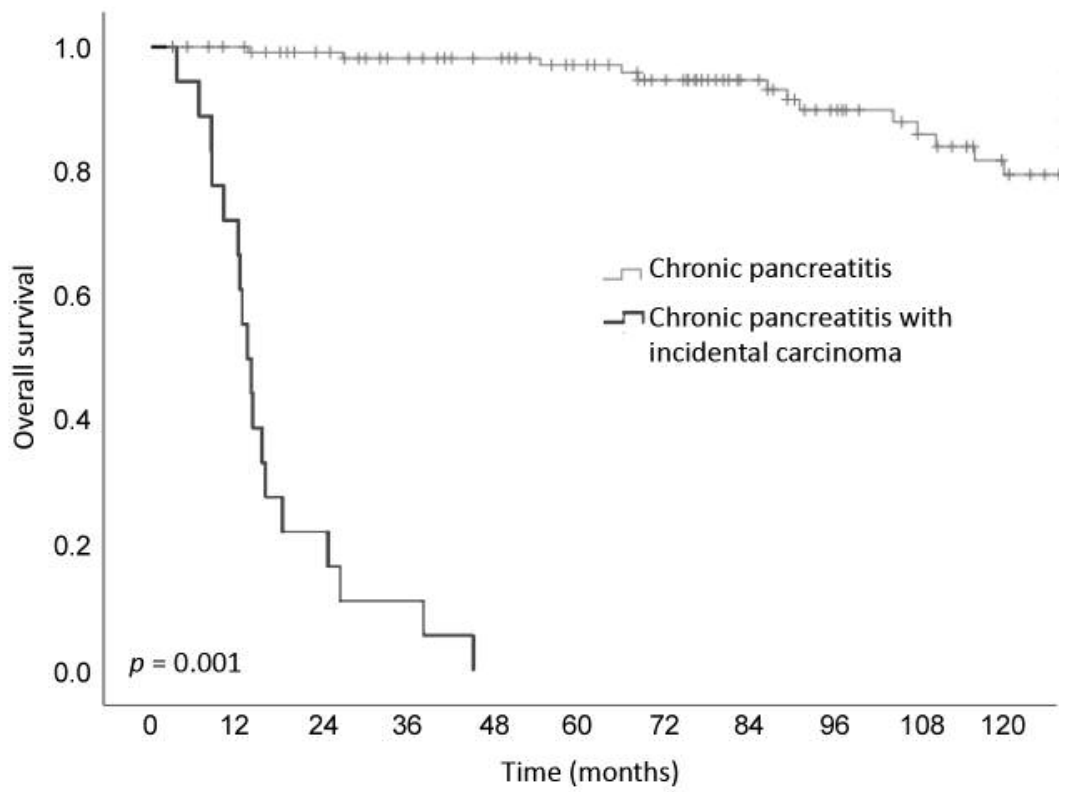

Figure 1. Overall survival of patients with exclusive chronic pancreatitis and those with chronic pancreatitis with incidental carcinoma.

Table II. Comparison of patients with exclusive chronic pancreatitis and chronic pancreatitis with incidental carcinoma.

\begin{tabular}{|c|c|c|c|}
\hline Characteristic & $\begin{array}{l}\text { Chronic pancreatitis } \\
\qquad(\mathrm{n}=234)\end{array}$ & $\begin{array}{l}\text { Chronic pancreatitis with } \\
\text { incidental carcinoma }(\mathrm{n}=18)\end{array}$ & $p$-Value \\
\hline Median age (range), years & $52.2(19-84)$ & $63.8(44-85)$ & 0.001 \\
\hline Mean preoperative bilirubin level (range), $\mathrm{mg} / \mathrm{dl}$ & $1.11(0.1-17.9)$ & $3.05(0.3-11.0)$ & 0.001 \\
\hline Mean preoperative amylase level (range), U/1 & $107.9(5-916)$ & $86.0(7-228)$ & 0.659 \\
\hline Preoperative ERCP, n (\%) & $134(57.3)$ & $15(83.3)$ & 0.576 \\
\hline Preoperative pancreatic or biliary stenting, $\mathrm{n}(\%)$ & $114(48.7)$ & $13(72.2)$ & 0.562 \\
\hline Mean preoperative CA19-9 (range), kU/1 & $53.6(3-1700)$ & $524.2(3-3798)$ & 0.001 \\
\hline POPF (grade B and C), n (\%) & $20(0.9)$ & $1(0.6)$ & 0.577 \\
\hline $\mathrm{PPH}, \mathrm{n}(\%)$ & $16(0.7)$ & $1(0.6)$ & 0.684 \\
\hline Postoperative bile leakage choledochojejunostomy, n (\%) & $11(0.5)$ & $1(0.6)$ & 0.556 \\
\hline Complication\#, n (\%) & $86(36.7)$ & $8(44.4)$ & 0.616 \\
\hline Mean length of hospital stay (range), days & $19.6(7-276)$ & $14.6(7-25)$ & 0.411 \\
\hline Reoperation within 30 days, $\mathrm{n}(\%)$ & $21(0.9)$ & $1(0.6)$ & 0.481 \\
\hline 30-Day mortality, n (\%) & $4(0.2)$ & $0(0.0)$ & $>0.99$ \\
\hline
\end{tabular}

ERCP: Endoscopic retrograde cholangiopancreatography; POPF: postoperative pancreatic fistula; $\mathrm{PPH}$ : postpancreatectomic hemorrhage. ${ }^{\#} \mathrm{Clavien}-$ Dindo grade $\geq 2$.

retrospectively evaluated the long-term outcome of 292 patients with $\mathrm{CP}$, demonstrated that patients who initially underwent surgery required fewer subsequent interventions, required shorter hospital stays, and had a better quality of life compared to those who underwent a solely endoscopic or conservative treatment (20). Others concluded that early operation might prevent functional and morphological irreversible damage to the gland (21). In our analysis, patients with $\mathrm{CP}$ and an incidental carcinoma who were treated operatively had a mean age of 63.8 years, while patients with $\mathrm{CP}$ alone had a mean age of 52.2 years. This additionally documents the early demand for a surgical procedure in order to intercept malignant transformation. In summary, the hypothesis that postponing surgery has a negative influence on treatment outcome appears therefore to be supported.

Admittedly, the debate regarding the choice of surgical procedure is still ongoing. Pancreaticoduodenectomy, pyloruspreserving pancreaticoduodenectomy, and duodenum-preserving 
Table III. Characteristics and outcome of patients with chronic pancreatitis and ductal adenocarcinoma.

\begin{tabular}{|c|c|c|c|c|c|c|}
\hline Patient & $\begin{array}{l}\text { Age, years/ } \\
\text { gender }\end{array}$ & $\begin{array}{l}\text { Surgical } \\
\text { procedure }\end{array}$ & $\begin{array}{c}\text { Preoperative CA19-9 } \\
\text { level }(\mathrm{kU} / \mathrm{l})\end{array}$ & $\begin{array}{l}\text { Complication, } \\
\mathrm{n}(\%)^{\#}\end{array}$ & $\begin{array}{l}\text { Pathology } \\
\text { (TNM) }\end{array}$ & $\begin{array}{l}\text { Death } \\
\text { (POD) }\end{array}$ \\
\hline A & $60 / \mathrm{M}$ & Pancreaticoduodenectomy & 378 & No & pT2 pN0 M0 G2 R0 & 427 \\
\hline B & $69 / \mathrm{M}$ & Pancreaticoduodenectomy & 152 & No & pT3 pN1 M0 G2 R1 & 203 \\
\hline $\mathrm{C}$ & $85 / \mathrm{F}$ & Pancreaticoduodenectomy & 411 & No & pT3 pN1 M0 G2 R0 & 1160 \\
\hline D & $58 / \mathrm{M}$ & Pancreaticoduodenectomy & 34 & Yes & pT3 pN1 M0 G3 R1 & 377 \\
\hline $\mathrm{E}$ & $52 / \mathrm{M}$ & Pancreaticoduodenectomy & 210 & No & pT3 pN1 M0 G3 R1 & 558 \\
\hline $\mathrm{F}$ & $55 / \mathrm{W}$ & Pancreaticoduodenectomy & 140 & No & pT2 pN0 M0 G2 R0 & 110 \\
\hline G & $45 / \mathrm{F}$ & Total pancreatectomy & 55 & No & pT3 pN1 M0 G3 R0 & 257 \\
\hline $\mathrm{H}$ & 69/M & Pancreaticoduodenectomy & 487 & No & pT3 pN1 M0 G3 R0 & 486 \\
\hline I & $78 / \mathrm{M}$ & Pancreaticoduodenectomy & 3798 & Yes & pT3 pN1 M0 G3 R0 & 259 \\
\hline $\mathrm{J}$ & $72 / \mathrm{W}$ & Pancreaticoduodenectomy & 636 & No & pT3 pN1 M1 G3 R1 & 307 \\
\hline K & $61 / \mathrm{M}$ & Pancreaticoduodenectomy & 520 & No & pT1 pN0 M0 G2 R0 & 408 \\
\hline $\mathrm{L}$ & $56 / \mathrm{M}$ & Pancreaticoduodenectomy & 41 & Yes & pT3 pN1 M0 G2 R0 & 750 \\
\hline M & $44 / \mathrm{M}$ & Pancreaticoduodenectomy & 112 & No & pT3 pN1 M0 G2 R0 & 1369 \\
\hline $\mathrm{N}$ & $68 / \mathrm{M}$ & Total pancreatectomy & 87 & No & pT3 pN1 M0 G3 R1 & 367 \\
\hline $\mathrm{O}$ & $77 / \mathrm{M}$ & Pancreaticoduodenectomy & 397 & Yes & pT3 pN0 M0 G2 R0 & 471 \\
\hline $\mathrm{P}$ & $56 / \mathrm{M}$ & Distal pancreatectomy & 50 & No & pT1 pN0 M0 G2 R0 & 387 \\
\hline Q & $74 / \mathrm{M}$ & Total pancreatectomy & 23 & Yes & pT3 pN0 M0 G2 R0 & 804 \\
\hline $\mathrm{R}$ & $70 / \mathrm{M}$ & Total pancreatectomy & 755 & No & pT3 pN0 M0 G3 R0 & 432 \\
\hline
\end{tabular}

F: Female, M: male, POD: postoperative day. ${ }^{\#}$ Clavien-Dindo grade $\geq 2$.

pancreatic head resection are important treatment options for patients with CP. However, results from a systematic review and meta-analysis indicated that all procedures are equally effective for the management of pain, postoperative morbidity, exocrine insufficiency, and endocrine insufficiency (22). Results from single-center trials showing superiority for duodenum-preserving pancreatic head resection were not confirmed in multicenter study (23). Because incidental pancreatic cancer cannot be ruled out with certainty, partial pancreatoduodenectomy in terms of pylorus-preserving pancreaticoduodenectomy or distal pancreatectomy are our procedure of choice because they allow adequate oncological treatment and avoid demand which might indicate reoperation.

In addition, numerous studies have found a strong link between $\mathrm{CP}$ and pancreatic cancer. Patients with hereditary pancreatitis and an early onset have a markedly increased risk at least 50-fold greater than the general population (7). Furthermore, a meta-analysis evidenced a relative risk of 13.3 for developing PDAC in patients with CP, with a 10-to 20-year lag between pancreatitis and development of pancreatic malignancy (24). In our analysis, histological examination showed ductal adenocarcinomas in $18(7.1 \%)$ patients, while the mean delay between initial diagnosis and operative intervention was 6.4 years. Consequently, the indication for early surgical intervention is substantiated and implementation into daily practice is demanded.

The present study is limited by common biases that are mainly due to the retrospective character of this analysis. Precision and completeness of data acquisition are very difficult to control, especially over such an extended study period. Furthermore, treatment regimens are altered over time. A strength of this study is the bi-national participation of two tertiary referral centers for pancreatic surgery, which remarkably enlarged the number of patients studied.

In conclusion, the results of our study demonstrate that pancreatic resection for $\mathrm{CP}$ may be considered technically feasible and safe. The high incidence of incidental pancreatic adenocarcinoma, however, underlines the necessity for an early surgical therapy approach for these patients. High-quality randomized controlled trails are needed to verify these results and facilitate evidence-based guidelines to guide clinicians in their decision making for subsequent intervention.

\section{References}

1 Kleeff J, Whitcomb DC, Shimosegawa T, Esposito I, Lerch MM, Gress T, Mayerle J, Drewes AM, Rebours V, Akisik F, Munoz JED and Neoptolemos JP: Chronic pancreatitis. Nat Rev Dis Primers 3: 17060, 2017.

2 Talamini G, Bassi C, Falconi M, Sartori N, Salvia R, Rigo L, Castagnini A, Di Francesco V, Frulloni L, Bovo P, Vaona B, Angelini G, Vantini I, Cavallini G and Pederzoli P: Alcohol and smoking as risk factors in chronic pancreatitis and pancreatic cancer. Dig Dis Sci 44: 1303-1311, 1999.

3 Stram M, Liu S and Singhi AD: Chronic Pancreatitis. Surg Pathol Clin 9: 643-659, 2016.

4 Muniraj T, Aslanian HR, Farrell J and Jamidar PA: Chronic pancreatitis, a comprehensive review and update. Part I: epidemiology, etiology, risk factors, genetics, pathophysiology and clinical features. Dis Mon 60: 530-550, 2014. 
5 Whitcomb DC, Frulloni L, Garg P, Greer JB, Schneider A, Yadav D and Shimosegawa T: Chronic pancreatitis: An international draft consensus proposal for a new mechanistic definition. Pancreatology 16: 218-224, 2016.

6 Hall TC, Garcea G, Webb MA, Al-Leswas D, Metcalfe MS and Dennison AR: The socio-economic impact of chronic pancreatitis: a systematic review. J Eval Clin Pract 20: 203-207, 2014.

7 Becker AE, Hernandez YG, Frucht H and Lucas AL: Pancreatic ductal adenocarcinoma: risk factors, screening and early detection. World J Gastroenterol 20: 11182-11198, 2014.

8 Misra SP, Thorat VK, Vij JC and Anand BS: Development of carcinoma in chronic calcific pancreatitis. Int $\mathrm{J}$ Pancreatol 6: 307-312, 1990

9 Lohr JM, Dominguez-Munoz E, Rosendahl J, Besselink M, Mayerle J, Lerch MM, Haas S, Akisik F, Kartalis N, IglesiasGarcia J, Keller J, Boermeester M, Werner J, Dumonceau JM, Fockens P, Drewes A, Ceyhan G, Lindkvist B, Drenth J, Ewald N, Hardt P, de Madaria E, Witt H, Schneider A, Manfredi R, Brondum FJ, Rudolf $\mathrm{S}$, Bollen $\mathrm{T}$, Bruno $\mathrm{M}$ and HaPan EUUEGWG: United European Gastroenterology evidence-based guidelines for the diagnosis and therapy of chronic pancreatitis (HaPanEU). United Eur Gastroenterol J 5: 153-199, 2017.

10 Hoffmeister A, Mayerle J, Beglinger C, Buchler MW, Bufler P, Dathe K, Folsch UR, Friess H, Izbicki J, Kahl S, Klar E, Keller J, Knoefel WT, Layer P, Loehr M, Meier R, Riemann JF, Runzi M, Schmid RM, Schreyer A, Tribl B, Werner J, Witt H, Mossner J, Lerch MM and Members of the Guideline Committee: English language version of the S3-Consensus Guidelines on Chronic Pancreatitis: Definition, aetiology, diagnostic examinations, medical, endoscopic and surgical management of chronic pancreatitis. Z Gastroenterol 53: 1447-1495, 2015.

11 Partington PF and Rochelle RE: Modified Puestow procedure for retrograde drainage of the pancreatic duct. Ann Surg 152: 1037-1043, 1960

12 Kagedan DJ, Ahmed M, Devitt KS and Wei AC: Enhanced recovery after pancreatic surgery: a systematic review of the evidence. HPB 17: 11-16, 2015.

13 Wente MN, Veit JA, Bassi C, Dervenis C, Fingerhut A, Gouma DJ, Izbicki JR, Neoptolemos JP, Padbury RT, Sarr MG, Yeo CJ and Buchler MW: Postpancreatectomy hemorrhage (PPH): An International Study Group of Pancreatic Surgery (ISGPS) definition. Surgery 142: 20-25, 2007.

14 Bassi C, Dervenis C, Butturini G, Fingerhut A, Yeo C, Izbicki J, Neoptolemos J, Sarr M, Traverso W, Buchler M and International Study Group on Pancreatic Fistula D: Postoperative pancreatic fistula: an international study group (ISGPF) definition. Surgery 138: 8-13, 2005.

15 Clavien PA, Barkun J, de Oliveira ML, Vauthey JN, Dindo D, Schulick RD, de Santibanes E, Pekolj J, Slankamenac K, Bassi C, Graf R, Vonlanthen R, Padbury R, Cameron JL and Makuuchi $\mathrm{M}$ : The Clavien-Dindo classification of surgical complications: five-year experience. Ann Surg 250: 187-196, 2009.
16 Issa Y, van Santvoort HC, Fockens P, Besselink MG, Bollen TL, Bruno MJ, Boermeester MA and Collaborators: Diagnosis and treatment in chronic pancreatitis: an international survey and case vignette study. HPB (Oxford) 19: 978-985, 2017.

17 Conwell DL, Lee LS, Yadav D, Longnecker DS, Miller FH, Mortele KJ, Levy MJ, Kwon R, Lieb JG, Stevens T, Toskes PP, Gardner TB, Gelrud A, Wu BU, Forsmark CE and Vege SS: American Pancreatic Association Practice Guidelines in Chronic Pancreatitis: Evidence-based report on diagnostic guidelines. Pancreas 43: 1143-1162, 2014.

18 Cahen DL, Gouma DJ, Nio Y, Rauws EA, Boermeester MA, Busch OR, Stoker J, Lameris JS, Dijkgraaf MG, Huibregtse K and Bruno MJ: Endoscopic versus surgical drainage of the pancreatic duct in chronic pancreatitis. N Engl J Med 356: 676-684, 2007.

19 Cahen DL, Gouma DJ, Laramee P, Nio Y, Rauws EA, Boermeester MA, Busch OR, Fockens P, Kuipers EJ, Pereira SP, Wonderling D, Dijkgraaf MG and Bruno MJ: Long-term outcomes of endoscopic $v s$. surgical drainage of the pancreatic duct in patients with chronic pancreatitis. Gastroenterology 141: 1690-1695, 2011.

20 Rutter K, Ferlitsch A, Sautner T, Puspok A, Gotzinger P, Gangl A and Schindl M: Hospitalization, frequency of interventions, and quality of life after endoscopic, surgical, or conservative treatment in patients with chronic pancreatitis. World J Surg 34: 2642-2647, 2010.

21 Nealon WH and Thompson JC: Progressive loss of pancreatic function in chronic pancreatitis is delayed by main pancreatic duct decompression. A longitudinal prospective analysis of the modified puestow procedure. Ann Surg 217: 458-466; discussion 466-458, 1993.

22 Zhao X, Cui N, Wang X, and Cui Y: Surgical strategies in the treatment of chronic pancreatitis: An updated systematic review and meta-analysis of randomized controlled trials. Medicine (Baltimore) 96: e6220, 2017.

23 Diener MK, Huttner FJ, Kieser M, Knebel P, Dorr-Harim C, Distler M, Grutzmann R, Wittel UA, Schirren R, Hau HM, Kleespies A, Heidecke CD, Tomazic A, Halloran CM, Wilhelm TJ, Bahra M, Beckurts T, Borner T, Glanemann M, Steger U, Treitschke F, Staib L, Thelen K, Bruckner T, Mihaljevic AL, Werner J, Ulrich A, Hackert T, Buchler MW, and ChroPac Trial G: Partial pancreatoduodenectomy versus duodenum-preserving pancreatic head resection in chronic pancreatitis: the multicentre, randomised, controlled, double-blind ChroPac trial. Lancet 390: 1027-1037, 2017.

24 Raimondi S, Lowenfels AB, Morselli-Labate AM, Maisonneuve $\mathrm{P}$, and Pezzilli R: Pancreatic cancer in chronic pancreatitis; aetiology, incidence, and early detection. Best Pract Res Clin Gastroenterol 24: 349-358, 2010. 